\title{
Characteristics, management, and outcome of ocular medulloepithelioma: systematic review of literature and case report
}

\author{
Yacoub A. Yousef ${ }^{1} \odot$, Shatha Hajja ${ }^{2}$, Hanood AbuRass ${ }^{3} \odot$, Mays AlJboor', Rashed Mustafa Nazzal ${ }^{4} \oplus$, \\ Katarzyna Nowomiejska ${ }^{4}$, Hussam Haddad ${ }^{3} \odot$, Iyad Sultan $^{2} \odot$ \\ 'Department of Surgery (Ophthalmology), King Hussein Cancer Centre, Amman, Jordan \\ ${ }^{2}$ Department of Paediatric Oncology,2 King Hussein Cancer Centre, Amman, Jordan \\ ${ }^{3}$ Department of Pathology, King Hussein Cancer Centre, Amman, Jordan \\ ${ }^{4}$ Department of Ophthalmic Surgery, Medical university of Lublin, Lublin, Poland
}

\begin{abstract}
BACKGROUND: Ocular medulloepithelioma (OM) is a rare ocular malignancy. This is a report of a rare case of medulloepithelioma that was misdiagnosed as retinoblastoma.

MATERIAL AND METHODS: A case report and review of published, peer-reviewed, English language literature reporting on ocular medulloepithelioma.

RESULTS: A seven-year-old girl presented with a white mass in the anterior chamber of her left eye. The initial diagnosis was retinoblastoma with anterior chamber invasion, and therefore it was enucleated. Microscopy showed a cellular tumour composed of malignant primitive cells forming sheets, rosettes, and tubular structures. Based on the presence of prominent pleomorphism the tumour was diagnosed as malignant teratoid medulloepithelioma. At last date of follow-up three years after enucleation, the patient was alive without metastasis. A systematic review of literature, analysed 177 cases of OM. The tumour was localised in the ciliary body in 134 (92\%) cases, and 26 $(23 \%)$ cases had extraocular extension. Primary management was enucleation in $84(55 \%)$ cases, tumour resection in $32(21 \%)$ cases, and radiation therapy in $20(13 \%)$ cases. Histopathology disclosed benign features in $36(22 \%)$ eyes, malignant features in 124 (78\%) eyes, teratoid features in $72(59 \%)$, and non-teratoid features in $51(41 \%)$ eyes. At a mean follow-up of five years, $14(8 \%)$ patients had metastasis, and six (6\%) patients were dead.

CONCLUSIONS: Ocular medulloepithelioma most commonly affects children. The most common type is the malignant teratoid type, but it has a favourable prognosis, and distant metastasis and mortality are relatively rare, at $8 \%$ and $6 \%$, respectively.
\end{abstract}

KEY WORDS: ciliary body; iris; medulloepithelioma; retinoblastoma; tumour 


\section{INTRODUCTION}

Ocular medulloepithelioma $(\mathrm{OM})$ is a rare embryonal tumour arising from the primitive medullary epithelium, along the inner layer of the optic cup [1-3]. It arises from the ciliary body from the non-pigmented ciliary epithelium of the pars plica$t a$, and rarely in the iris, retina, or optic nerve head [3-5]. This tumour is similar to medulloepithelioma of the central nervous system, but intraocular medulloepithelioma rarely affects adults and usually affects the ciliary body in children (median age 3.8 years; range 6 months to 41 years) [6-8]. Ocular medulloepithelioma is a non-hereditary tumour, but it can be a manifestation of a tumour predisposition syndrome associated with DICER1-related pleuro-pulmonary blastoma [9-11]. Ocular medulloepithelioma was named diktyoma in 1908 due to the presence of a network of medullary epithelial bands in this tumour, and in 1931 the term medulloepithelioma was introduced, and this has been the favoured terminology since then $[12,13]$.

Features of malignancy in OM are not well defined. They include the presence of sheets of poorly differentiated neuroblastic cells, involvement of ocular and extra ocular tissue, the presence of sarcomatous features, and the degree of mitotic activity and pleomorphism, and they are classified into non-teratoid or teratoid type, and benign or malignant $[1,2,6-8]$. Of two relatively large case series of medulloepithelioma in the literature (56 cases by Broughton and Zimmerman [7], and 41 cases by Kaliki et al. [10]), 50-63\% were non-teratoid, $37-50 \%$ were teratoid, and around $80 \%$ were of malignant type. Herein we report a case of medulloepithelioma in a seven-year-old girl, as well as a systematic review of the published literature about ocular medulloepithelioma to summarise the reported clinical and histopathological features, treatments, and outcome of OM.

\section{MATERIAL AND METHODS}

A search of the published, peer-reviewed literature reporting on ocular medulloepithelioma by MEDLINE search with key words "Medulloepithelioma, Ciliary body tumor, Ocular tumor" was conducted up to March 2017. We also examined the reference lists of the reports. We analysed in detail all case series and case reports that described ocular medulloepithelioma. We excluded all cases with any diagnosis other than medulloepithelioma as well as reports in languages other than English for which a translation was not available. Outcome measures included: demographics, presentation, clinical features, histopathologic features (benign vs. malignant and teratoid vs. non teratoid), extent of the disease, therapeutic interventions, management outcome, site of metastasis, and survival data.

For the sake of calculating the percentage for any outcome in this analysis when the outcome measure was not available for the group of patients, we referred the percentage to the number of patients with known outcome, excluding those with unknown outcome.

\section{RESULTS}

A review of Medline literature before March 2017 identified 205 cases of intra ocular medulloepithelioma. We included the cases we are reporting here, and we excluded 10 cases from articles not in English language and 17 cases because of possible duplication or inadequate data for analysis. The overall number of cases eligible for analysis was 177 .

\section{CASE REPORT}

A seven-year-old girl, who was diagnosed with glaucoma at the age of two years and had a drainage device inserted at the age of four years, presented with a white mass in the anterior chamber of her left eye (Fig. 1). The initial diagnosis was retinoblastoma with anterior chamber invasion vs. medulloepithelioma, and therefore it was enucleated. The enucleated eye showed a $2.1 \times 1.2 \mathrm{~cm}$ grey-white tumour located mainly in the anterior chamber. A plastic glaucoma drainage device was attached to the eye. Microscopy showed a cellular tumour composed of malignant primitive cells forming sheets, rosettes, and tubular struc-
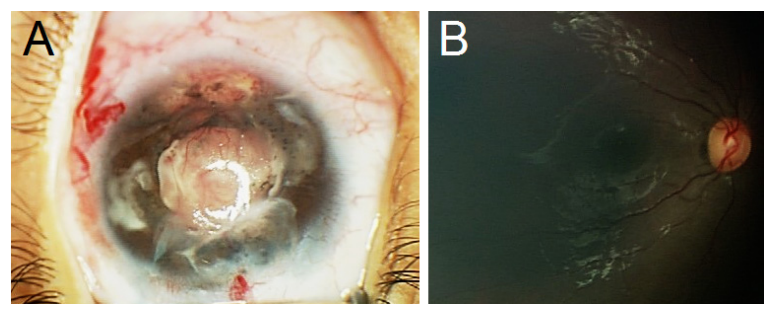

FIGURE 1. A. Left eye presented with leukocoria due to presence of retrolental cyclitic membrane associated with anterior chamber invasion of this white mass superiorly. B. Right eye showed normal fundus exam. Initial diagnosis was retinoblastoma with anterior chamber invasion vs. medulloepithelioma 

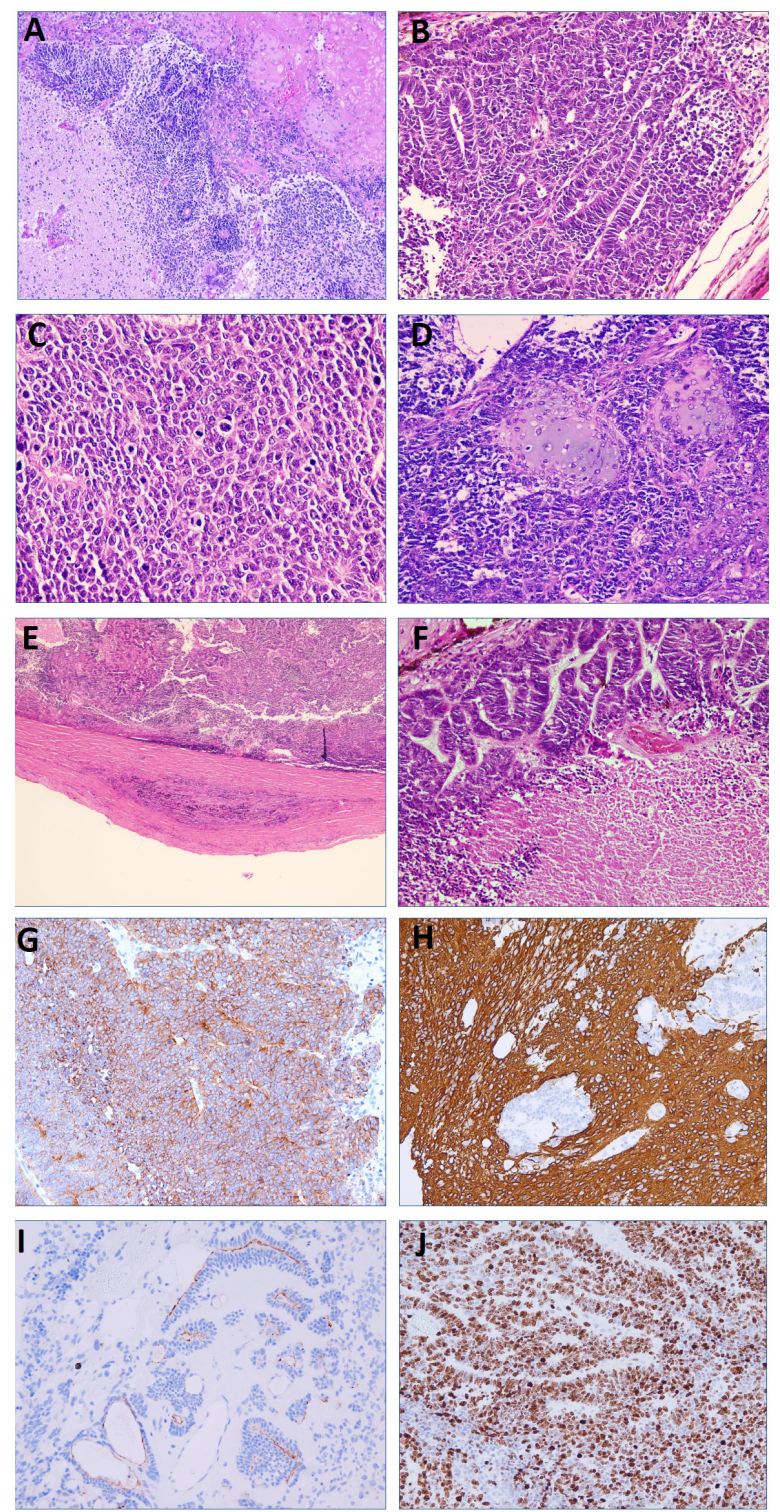

FIGURE 2. Medulloepithelioma was diagnosed based on microscopy that showed cellular tumour composed of epithelium, glial tissue (A), and tubular structures (B). The tumour exhibited numerous mitotic figures with prominent pleomorphic of poorly differentiated neuroepithelium (C), few foci of cartilage (D), scleral invasion (E), and necrosis (F). The tumour cells were positive for synaptophysin (G) and GFAP in the astrocytic component (H). EMA was focally positive with a luminal pattern (I), and the Ki67 LI was around $80 \%(\mathbf{J})$

tures. The tumour exhibited numerous mitotic figures with prominent pleomorphism and areas of necrosis (Fig. 2). It also harboured heterotopic elements in the form of astrocytic tissue and a few foci of cartilage. No sarcomatous features were present. The tumour cells were positive for synaptophysin. EMA was focally positive with a luminal pattern. GFAP was positive in the astrocytic component. The Ki-67 labelling index was around
$80 \%$ (Fig. 2). Most of the tumour was located in the anterior chamber with involvement of the vitreous, cornea, and sclera. The optic nerve and disc were free of tumour. Based on the presence of heterotopic elements, primitive neuroblastic differentiation, invasion of the sclera and cornea, numerous mitotic figures, and prominent pleomorphism, the tumour was diagnosed as malignant teratoid medulloepithelioma. At last date of follow-up three years after enucleation, the patient was alive without metastasis.

\section{PATIENTS AND CLINICAL CHARACTERISTICS}

Out of 177 patients analysed in this review, there were 72 males ( $49 \%$ of 148 with reported gender) and 76 females $(51 \%)$; the mean age at time of diagnosis was nine years (range, 1-79 years); only $18(10 \%)$ patients were diagnosed after the age of 10 years. The presentation was variable between the reported cases. Fifty-three (56\% of 94 with reported presentation) patients presented with leukocoria or intraocular mass, eight (9\%) patients presented with proptosis, eight (9\%) patients presented with squint, eight (9\%) patients presented with buphthalmos, $14(15 \%)$ patients presented with eye pain, and three $(3 \%)$ patients were diagnosed incidentally. In 83 (47\% - the percentage here is confusing because it makes the sum $147 \%$, so I prefer not to mention the percentage) patients the presentation was not mentioned (Tab. I). The tumour was in the ciliary body in $134(92 \%)$ cases, in the retina in four $(3 \%)$ cases, in the optic nerve in eight $(5 \%)$ cases, while it was not mentioned in the remaining $31(18 \%)$ patients. Extraocular tumour extension was reported in 26 (23\% of 114 cases), and no extraocular tumour extension was seen in 88 (77\%) cases, while it was not mentioned in the remaining $63(36 \%)$ cases (Tab. II).

\section{PATHOLOGIC CHARACTERISTICS}

Regarding tumour pathologic features; 124 (78\%) eyes harboured malignant tumours, and 36 (22\%) eyes harboured benign tumours, while it was not mentioned in the remaining 17 (10\%) patients. Seventy-two (59\%) tumours were of teratoid type, $51(41 \%)$ were of non-teratoid type, and the type was not mentioned in the remaining 54 (31\%) patients. Out of the 36 benign tumours, 12 (39\%) were teratoid and 19 (61\%) were non-teratoid, and out of the 124 malignant tumours, 60 (65\%) were teratoid and $32(35 \%)$ were non-teratoid. In five $(14 \%)$ of the benign tumours and $32(26 \%)$ of the 


\begin{tabular}{|l|c|c|c|c|}
\hline Table I. Patients' demographics & Number & \% & Adjusted* \% \\
\hline Number & & 177 & & \\
\hline Age & Mean & 9 years & & \\
\hline & Range & $1-79$ years & & 49 \\
\hline & & & & 51 \\
\hline Gender & Male & 72 & 43 & - \\
\hline & Female & 76 & 16 & 56 \\
\hline & NA** & 29 & 30 & 9 \\
\hline Presentation & Mass or leukocoria & 53 & 5 & 9 \\
\hline & Proptosis & 8 & 5 & 9 \\
\hline & Buphthalmos & 8 & 5 & 3 \\
\hline & Squint & 8 & 2 & 15 \\
\hline
\end{tabular}

* For the sake of calculating the percentage for any outcome in this analysis when the outcome measure was not available for group of the patients, we referred the percentage to the number of patients with known outcome, excluding those with unknown outcome; **NA - these outcome data were not reported in the original article reporting about these patients

\begin{tabular}{|c|c|c|c|c|}
\hline & & Number & $\%$ & Adjusted* \% \\
\hline \multirow[t]{4}{*}{ Location } & Ciliary body & 134 & 76 & 92 \\
\hline & Retina & 4 & 2 & 3 \\
\hline & Optic nerve & 8 & 5 & 5 \\
\hline & $N A^{* *}$ & 31 & 18 & - \\
\hline \multirow[t]{3}{*}{ Extraocular extension } & No & 88 & 50 & 77 \\
\hline & Yes & 26 & 15 & 23 \\
\hline & $N A^{* *}$ & 63 & 36 & - \\
\hline \multirow[t]{12}{*}{ Pathology } & Teratoid & 72 & 41 & 59 \\
\hline & Non Teratoid & 51 & 29 & 41 \\
\hline & $N A^{* *}$ & 54 & 31 & - \\
\hline & Benign & 36 & 20 & 22 \\
\hline & Teratoid & 12 & 33 & 39 \\
\hline & Non Teratoid & 19 & 53 & 61 \\
\hline & $N A^{* *}$ & 5 & 14 & - \\
\hline & Malignant & 124 & 70 & 78 \\
\hline & Teratoid & 60 & 48 & 65 \\
\hline & Non Teratoid & 32 & 26 & 35 \\
\hline & $N A^{* *}$ & 32 & 26 & - \\
\hline & $N A^{\star *}$ & 17 & 10 & - \\
\hline
\end{tabular}

*For the sake of calculating the percentage for any outcome in this analysis when the outcome measure was not available for group of the patients, we referred the percentage to the number of patients with known outcome, excluding those with unknown outcome; **NA — these outcome data were not reported in the original article reporting about these patients 


\begin{tabular}{|c|c|c|c|c|}
\hline & & Number & $\%$ & Adjusted* \% \\
\hline \multirow[t]{6}{*}{ Primary Treatment } & Enucleation & 84 & 47 & $55 \%$ \\
\hline & Tumour resection & 32 & 18 & $21 \%$ \\
\hline & Plaque radiotherapy & 15 & 8 & $10 \%$ \\
\hline & $\begin{array}{l}\text { External beam } \\
\text { radiotherapy }\end{array}$ & 5 & 3 & $3 \%$ \\
\hline & Others** & 17 & 10 & $11 \%$ \\
\hline & $N A^{* \star *}$ & 24 & 14 & - \\
\hline \multirow[t]{3}{*}{ Eye Salvage } & Yes & 56 & 32 & $69 \%$ \\
\hline & NO & 25 & 14 & $31 \%$ \\
\hline & $N A^{* \star *}$ & 121 & 68 & - \\
\hline \multirow[t]{3}{*}{ Metastasis } & No & 152 & 86 & $92 \%$ \\
\hline & Yes & 14 & 8 & $8 \%$ \\
\hline & $N A^{* * *}$ & 11 & 6 & - \\
\hline \multirow[t]{3}{*}{ Mortality } & Alive & 91 & 51 & $94 \%$ \\
\hline & Dead & 6 & 3 & $6 \%$ \\
\hline & $N A^{* * *}$ & 63 & 36 & - \\
\hline \multirow[t]{2}{*}{ Follow up } & Mean & 5 years & & \\
\hline & Range & \multicolumn{2}{|c|}{$1-25$ years } & \\
\hline
\end{tabular}

*For the sake of calculating the percentage for any outcome in this analysis when the outcome measure was not available for group of the patients, we referred the percentage to the number of patients with known outcome, excluding those with unknown outcome; ${ }^{* *} 0$ thers: cryotherapy in 5 cases, palliative chemotherapy in 5 cases, and exenteration in 7 cases; ***NA - these outcome data were not reported in the original article reporting about these patients

malignant tumours, the teratoid vs. non-teratoid type was not mentioned. No patients in this review had a family history of medulloepithelioma, and all of them had unilateral disease (Tab. II).

\section{MANAGEMENT AND OUTCOME}

The primary treatment of the reported eyes was variable between different reports; 84 eyes $(55 \%)$ were treated by enucleation, 32 eyes $(21 \%)$ by tumour resection, $21(13 \%)$ by radiation (15 eyes by radioactive plaque therapy, five eyes by external beam radiation therapy), and seven eyes were treated by exenteration. The primary treatment was not mentioned for 24 (14\%) eyes (Tab. III). At a mean follow-up of five years (range 1-25 years), out of the 81 eyes for which the status of the eye globe was described, 56 (69\%) eyes were salvaged, and 25 (31\%) eyes were not. At the last date of follow-up, 14 (8\%) patients were reported to have metastasis, and six (6\%) patients were dead. One had bone metastasis, nine had lymphatic metastasis to the neck (four of them were in the parotid gland), and the site of metastasis was not mentioned in eight cases.

\section{DISCUSSION}

Similar to retinoblastoma, which is the most common intraocular malignant tumour in children, $90 \%$ of cases are diagnosed before the age of five years [14]. Medulloepithelioma is another rare childhood disease. Kaliki et al. [10], in an analysis of 41 cases of OM from the USA and India, found that $85 \%$ of patients were children; similarly, in our systematic review of 177 patients including the 41 patients described in that study, the mean age at diagnosis was nine years, which is older than the age of diagnosis of retinoblastoma. However, the possibility of medulloepithelioma still exists in adults $[10,15-18]$. It is not known if this later diagnosis of OM compared to retinoblastoma is due to delayed 
event of tumour initiation or due to delayed diagnosis. Most cases of OM present due to associated secondary effects on the eye like glaucoma ( $44 \%$ to $60 \%)$ or a drop in vision due to a cataract $(26 \%$ to $50 \%)$, or a mass obstructing the visual access $[6,10$, $19,20]$. In our review, half of the cases presented with a large mass causing leukocoria, which indicates a large, long-standing tumour. Therefore, it is believed that the later age of diagnosis of medulloepithelioma may be due to the difficulty in directly visualising the ciliary body mass because of its anatomical location until it produces clinically detectable side effects. In addition to that, initial mismanagement of ciliary body medulloepithelioma is common, which may result in delayed diagnosis [6, 20, 21]. The differential diagnosis includes other malignant ocular tumours such as retinoblastoma and malignant melanoma, in addition to secondary involvement by extraocular tumours such as Ewing's sarcoma/PNET, rhabdomyosarcoma, and neuroblastoma. In our case report, the patient was misdiagnosed initially as atypical retinoblastoma with anterior chamber and ciliary body invasion, and the diagnosis of medulloepithelioma was pathological.

Medulloepithelioma displays a unique propensity to produce a retrolental neoplastic cyclitic membrane that is an extension of the tumour $[6,10]$. This cyclitic membrane serves as an important feature to differentiate medulloepithelioma from retinoblastoma and Coats' disease. Fluorescein angiography shows rapid filling of large, haphazard vessels emanating from the ciliary body across the hyaloid face in the case of medulloepithelioma, whereas the vessels are regular, organised, and emanate from the closed central funnel of the detachment out toward the ciliary body region in the case of retinoblastoma or Coats' disease [22, 23]. Medulloepithelioma can also be confused with persistent hyperplastic primary vitreous (PHPV) in some cases, but it shows a tendency to grow along the scaffold of the hyaloid and the retinal surface unlike PHPV [24-26]. On the other hand, similar to retinoinvasive melanoma, medulloepithelioma can rarely invade the retina, and therefore is called retinoinvasive medulloepithelioma mainly in chronic cases in older patients who present with glaucoma [27].

Features of malignancy in OM are not well defined. They include the presence of sheets of poorly differentiated neuroblastic cells resembling those of retinoblastoma with or without rosettes; sarcomatous areas resembling chondrosarcoma, rhabdomyosarcoma, or embryonal sarcoma, nuclear pleomorphism, or mitotic activity; and invasion of the uvea, cornea, or sclera with or without extrascleral extension [6, 19], and this is different than acquired epithelioma (adenoma or adenocarcinoma) of the nonpigmented ciliary epithelium that affects adults, and it has no embryonic features histopathologically [28]. In our review, only $18(10 \%)$ patients were diagnosed after the age of 10 years. Also, on histopathologic examination, non-teratoid medulloepithelioma discloses proliferation of primitive medullary epithelium, whereas teratoid medulloepithelioma harbours heteroplastic elements (most frequently hyaline cartilage, in addition to rhabdomyoblasts, striated muscle, and brain-like tissue) and proliferation of the neuroepithelial elements [1, 10. 19]. In this review, 78\% of cases were malignant, and $65 \%$ of the malignant tumours were teratoid, while only $39 \%$ of the benign tumours showed a teratoid component.

Treatment options for OM include local resection, radiation therapy (radioactive plaque therapy and external beam radiotherapy), enucleation, and rarely exenteration $[6,8,19,30,31]$. The role of systemic chemotherapy in the treatment of OM is not well established [32]. In our review, enucleation was the treatment modality for more than half of the cases, followed by local resection in $21 \%$ of cases. However, plaque radiotherapy (apex dose of $40 \mathrm{~Gy}$ ) was used with a high success rate in $10 \%$ of cases. Local resection can be considered for small circumscribed tumours (less than three clock hours), but the tumour recurrence rate is high for large tumours $(50-100 \%)[8,10,19]$. This high recurrence rate may be due to the presence of thin membranes of tumour cells, which are invisible intraoperatively, as we mentioned before.

Because of the rarity of $\mathrm{OM}$, limited data are available about its prognosis. The prognosis of OM depends on the origin of the tumour, extraocular extension, and intracranial extension, and it is better for ciliary medulloepithelioma without extraocular or intracranial extension [1, 4]. Ocular medulloepithelioma has a known systemic association with pleuropulmonary blastoma. It is postulated that $1 \%$ of patients with pleuropulmonary blastoma develop OM, and 5\% of patients with medulloepithelioma have a history of pleuropulmonary blastoma $[10,11]$. Similarly to our data, metastatic disease from ciliary body medulloepithelioma was reported in $8 \%$ of cases, most of which had extraocular tumour extension $[6,9,10$, 19]. Khaliki et al. described three cases with me- 
tastasis, all of which presented with extraocular tumour extension into the conjunctiva or the orbit. In contrary to metastatic retinoblastoma, which most commonly affect the brain and/or the bone marrow [33], metastatic medulloepithelioma is to the lymphatics in $90 \%$ of cases.

\section{CONCLUSION}

In conclusion, ciliary body medulloepithelioma is a rare unilateral disease that affects children, and it usually presents with leukocoria or an intraocular mass that can be misdiagnosed as retinoblastoma, Coats' disease, or PHPV. Enucleation is the most popular treatment for large tumours, even though tumour resection and radiation therapy may play a role in the management small tumours. Medulloepithelioma-associated mortality is rare and usually associated with extraocular tumour extension and metastasis toward lymphatics.

\section{ACKNOWLEDGEMENTS}

None.

\section{STATEMENT OF COMPETING INTERESTS}

None.

\section{REFERENCES}

1. Zimmerman LE. Verhoeff's "terato-neuroma". A critical reappraisal in light of new observations and current concepts of embryonic tumors. The Fourth Frederick H. Verhoeff Lecture. Am J Ophthalmol. 1971; 72(6): 1039-1057, indexed in Pubmed: 4110093.

2. Zimmerman LE, Broughton WLA. Clinicopathologic and follow up study of fifty-six cases of intraocular medulloepithelioma. In: Jakobiec FA. ed. Ocular Adnexal Tumors. Aesculapius Publishing, Birmingham, AL 1978: 181-196.

3. Verhoeff FH. A rare tumor arising from the pars ciliaris retinae (teratoneuroma) of a nature hitherto unrecognized, and its relation to the so-called glioma-retinae. Trans Am Ophthalmol Soc. 1904; 10(Pt 2): 351-377, indexed in Pubmed: 16692035.

4. Vadmal M, Kahn E, Finger P, et al. Nonteratoid medulloepithelioma of the retina with electron microscopic and immunohistochemical characterization. Pediatr Pathol Lab Med. 1996; 16(4): 663-672, indexed in Pubmed: 9025863.

5. Takei H, Florez L, Moroz K, et al. Medulloepithelioma: Two unusual locations. Pathol Int. 2007; 57(2): 91-95, doi: 10.1111/j.14401827.2006.02062.x, indexed in Pubmed: 17300673.

6. Shields J, Eagle R, Shields C, et al. Congenital Neoplasms of the Nonpigmented Ciliary Epithelium (medulloepithelioma). Ophthalmology. 1996; 103(12): 1998-2006, doi: 10.1016/s0161-6420(96)30394-1.

7. Broughton WL, Zimmerman LE. A clinicopathologic study of 56 cases of intraocular medulloepitheliomas. Am J Ophthalmol. 1978; 85(3): 407-418, doi: 10.1016/s0002-9394(14)77739-6, indexed in Pubmed: 655220.

8. Shields J, Eagle R, Shields C, et al. Congenital Neoplasms of the Nonpigmented Ciliary Epithelium (medulloepithelioma). Ophthalmology. 1996; 103(12): 1998-2006, doi: 10.1016/s0161-6420(96)30394-1.

9. Shields JA, Shields CL. Tumors of the nonpigmented ciliary epithelium. In: Shields JA, Shields CL. ed. Intraocular Tumors: An Atlas and Textbook. 2nd ed. Lippincott Williams and Wilkins, Philadelphia, PA 2008: 482-490.
10. Kaliki S, Shields C, Eagle R, et al. Ciliary Body Medulloepithelioma. Ophthalmology. 2013; 120(12): 2552-2559, doi: 10.1016/j. ophtha.2013.05.015.

11. Priest JR, Williams GM, Manera R, et al. Ciliary body medulloepithelioma: four cases associated with pleuropulmonary blastoma - a report from the International Pleuropulmonary Blastoma Registry. Br J Ophthalmol. 2011; 95(7): 1001-1005, doi: 10.1136/bjo.2010.189779, indexed in Pubmed: 21156700.

12. Fuchs $E$. Growths and tumors of the ciliary epithelium [in German]. Albrecht Von Graefes Arch Ophthalmol. 1908; 68: 534-87.

13. Grinker RR. Gliomas of the retina including results of studies with silver impregnations. Arch Ophthalmol. 1931; 5: 920-935, doi: 10.1001/ archopht.1931.00820060088009.

14. Pendergrass TW, Davis S. Incidence of retinoblastoma in the United States. Arch Ophthalmol. 1980; 98(7): 1204-1210, doi: 10.1001/ archopht.1980.01020040056003, indexed in Pubmed: 7396771.

15. Litricbin 0. Latkovi_c Z. Malignant teratoid medulloepithelioma in an adult. Ophthalmologica. 1985; 191: 17-21.

16. Floyd BB, Minckler DS, Valentin L. Intraocular medulloepithelioma in a 79-year-old man. Ophthalmology. 1982; 89(9): 1088-1094, doi: 10.1016/s0161-6420(82)34679-5, indexed in Pubmed: 7177573.

17. Pushker N, Khuraijam N, Sen S, et al. Medulloepithelioma of the ciliary body associated with massive intravitreal hemorrhage in an adult. Can J Ophthalmol. 2008; 43(2): 253-254, doi: 10.3129/i08-022, indexed in Pubmed: 18347644.

18. Wolter JR, James BR. Adult type of medullo-epithelioma of the ciliary body. Am J Ophthalmol. 1958; 46(1 Pt 1): 19-26, doi: 10.1016/s00029394(14)78067-5, indexed in Pubmed: 13545305.

19. Broughton WL, Zimmerman LE. A clinicopathologic study of 56 cases of intraocular medulloepitheliomas. Am J Ophthalmol. 1978; 85(3): 407-418, doi: 10.1016/s0002-9394(14)77739-6, indexed in Pubmed: 655220

20. Kaliki S, Eagle RC, Grossniklaus HE, et al. Inadvertent implantation of aqueous tube shunts in glaucomatous eyes with unrecognized intraocular neoplasms: report of 5 cases. JAMA Ophthalmol. 2013; 131(7): 925-928, doi: 10.1001/jamaophthalmol.2013.828, indexed in Pubmed: 23699787.

21. Alkatan $\mathrm{H}$, Al-Amry M, Al-Hussain $\mathrm{H}$, et al. Medulloepithelioma of the ciliary body: the delay in diagnosis and frequent initial mismanagement. Can J Ophthalmol. 2011; 46(5): 431-438, doi: 10.1016/j. jcjo.2011.07.007, indexed in Pubmed: 21995988.

22. Sharma P, Shields CL, Turaka K, et al. Ciliary body medulloepithelioma with neoplastic cyclitic membrane imaging with fluorescein angiography and ultrasound biomicroscopy. Graefes Arch Clin Exp Ophthalmol. 2011; 249(8): 1259-1261, doi: 10.1007/s00417-011-1688-7, indexed in Pubmed: 21505878.

23. Shields JA, Eagle RC, Shields CL, et al. Fluorescein angiography and ultrasonography of malignant intraocular medulloepithelioma. J Pediatr Ophthalmol Strabismus. 1996; 33: 193-196.

24. Shields JA, Shields CL, Schwartz RL. Malignant teratoid medulloepithelioma of the ciliary body simulating persistent hyperplastic primary vitreous. Am J Ophthalmol. 1989; 107(3): 296-298, doi: 10.1016/0002-9394(89)90318-8, indexed in Pubmed: 2923158.

25. Font RL, Rishi K. Diffuse retinal involvement in malignant nonteratoid medulloepithelioma of ciliary body in an adult. Arch Ophthalmol. 2005; 123(8): 1136-1138, doi: 10.1001/archopht.123.8.1136, indexed in Pubmed: 16087851.

26. Carrillo R, Streeten BW. Malignant teratoid medulloepithelioma in an adult. Arch Ophthalmol. 1979; 97(4): 695-699, doi: 10.1001/ archopht.1979.01020010347012, indexed in Pubmed: 426684.

27. Kivelä T, Summanen P. Possible shared pathogenesis of the retinoinvasive phenotype of malignant medulloepithelioma and malignant melanoma of the ciliary body. Arch Ophthalmol. 2006; 124(7): 1066; author reply 1067, doi: 10.1001/archopht.124.7.1066, indexed in Pubmed: 16832040.

28. Shields J, Eagle R, Shields C, et al. Acquired Neoplasms of the Nonpigmented Ciliary Epithelium (adenoma and adenocarcinoma). Ophthalmology. 1996; 103(12): 2007-2016, doi: 10.1016/s01616420(96)30393-x. 
29. Monchy D, Jacquiot P, Dubourdieu D, et al. [Malignant teratoid medulloepithelioma of the ciliary body. Apropos of a case and review of the literature]. Arch Anat Cytol Pathol. 1993; 41(2): 107-112, indexed in Pubmed: 8239746.

30. Cassoux N, Charlotte F, Sastre X, et al. Conservative surgical treatment of medulloepithelioma of the ciliary body. Arch Ophthalmol. 2010; 128(3): 380-381, doi: 10.1001/archophthalmol.2009.404, indexed in Pubmed: 20212214

31. Ramasubramanian A, Shields CL, Kytasty C, et al. Resection of intraocular tumors (partial lamellar sclerouvectomy) in the pediatric age group. Ophthalmology. 2012; 119(12): 2507-2513, doi: 10.1016/j. ophtha.2012.06.044, indexed in Pubmed: 22917889.

32. Meel R, Chawla B, Mohanti BK, et al. Ocular medulloepithelioma chemosensitivity. Ophthalmology. 2010; 117(12): 2440. e1-2440.e2, doi: 10.1016/j.ophtha.2010.05.008, indexed in Pubmed: 20947172.

33. Hu HM, Zhang WL, Wang YZ, et al. [Clinical features, treatment and prognosis of retinoblastoma in distant metastasis stage]. Zhonghua Yan Ke Za Zhi. 2017; 53(2): 121-127, doi: 10.3760/cma.j.is sn.0412-4081.2017.02.010, indexed in Pubmed: 28260363. 